\title{
Medication Reconcilation: "You will find it only if you look for it"
}

\author{
Mohseenkhan Munshi ${ }^{1 *}$ and Sanjith Saseedharan ${ }^{2}$
}

1'Department of Clinical Pharmacy, S L Raheja-A fortis associate hospital, Raheja rugnalaya marg, Mahim (west), Mumbai-400016, India.

${ }^{2}$ HOD-Department of Critical Care, S L Raheja-A fortis associate hospital, Raheja rugnalaya marg, Mahim (west), Mumbai-400016, India.

\begin{abstract}
Introduction: The process of identifying the most accurate list of all medications that the patient is taking, including name, dosage, frequency, and route, by comparing the medical record to an external list or container of medications obtained from a patient, hospital, or other provider is known as medication reconciliation. Medication error ranks at the top among the preventable errors and mishaps in the field of medicine. Objective: To study the frequency of errors as a result of medication reconciliation and to study role of clinical pharmacist in the picking up of the same. Methods: Repeat history taking and previous paper review by a dedicated clinical pharmacist over a period of 3 months in 20 bedded tertiary care ICU in Mumbai, India. For this purpose a dedicated medication reconciliation form was constituted. Drug interactions were also studied by the clinical pharmacist. Results: In $42.86 \%$ cases drug interactions were noted. In almost $8 \%$ of cases there was improper history taken while medication omission was noted in $2.98 \%$ cases. In $45.23 \%$ of cases no discrepancy was noted. Conclusion: Medication errors are very common in the intensive care unit and medical reconciliation by a dedicated clinical pharmacist may go a long way in preventing mishaps in medication use in our intensive care units.
\end{abstract}

Key words: Discrepancies, Drug interaction, Medication reconciliation, Serious interaction, Significant interaction.

\section{INTRODUCTION}

Medication errors form one of the preventable errors in medicine. ${ }^{1}$ Presently every healthcare organization is moving towards providing safe, effective and affordable healthcare. Thus any preventable error can prove very expensive as it can potential increase length of stay, resulting in increased cost of hospital resources. This medication misadventure can also be an issue for medico-legal compensation. India alone records around 5.2 million injuries each year due to medical errors and adverse events of which one of the biggest contributions seems to arise from medication errors. ${ }^{2-4}$ As per reports in the past a patient is subjected to as much as 1 medication error per day. ${ }^{5}$ Medication errors are the thirds most frequent of the sentinel events primarily because of the complex and tedious process flow right from, Constituting, packaging, nomenclature, storage, dispensing etc.6 Communication failure or breakdown between consultants and nurses, nurses and patients and doctors and patients seems to be one of the factors responsible for medication errors.

Submitted date : $13 / 01 / 2015$ Revised date : $: 21 / 09 / 2015$ Accepted date :05/10/2015

Medicines reconciliation has been defined Dol: 10.5530/jopp.8.3.3 by the Institute for Healthcare Improvement as "the process of identifying the most accurate list of a patient's current medicines - including the name, dosage, frequency and route-and comparing them to the current list in use, recognizing and discrepancies, and documenting any changes, thus resulting in a complete list of medications, accurately communicated".

This process comprises five steps:

- develop a list of current medications;

- develop a list of medications to be prescribed;
Address for correspondence: Mr. Mohseenkhan Munshi Department of Clinical Pharmacy, SLRaheja-A fortis associate hospital, Raheja rugnalaya marg, Mahim (west), Mumbai-400016, India.

E-mail:mohseen_ph@yahoo. co.in

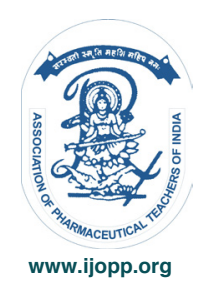


- compare the medications on the two lists;

- make clinical decisions based on the comparison; and

- Communicate the new list to appropriate caregivers and to the patient.

Presently this process in India (and in our hospital) is done by a good detailed history taken by the doctor, and then confirmed by the nurses (as in our institute) and then by scrutiny of the previous discharge card/ prescription notes if any. At times a clinical pharmacist is also part of this process. Unfortunately in view of the huge population and the dismal doctor patient ratio and nurse patient ratio the above practice is done quite quickly and detailed evaluation takes a backseat many a times.

The three disciplines-medicine, pharmacy and nursing have very little agreement on each other's role in the process and hence there is lot of data duplication and unnecessary paperwork which rarely results in resolving the problem.

In order to study the situation in our tertiary care intensive care unit, we decided to study

- How medication histories were being taken

- What were the various reasons for medication errors

- What was the rate of interactions not being highlighted after transcription of the medicines on the drug order sheets

\section{MATERIAL AND METHODS}

We conducted this study in our tertiary care 20 bedded ICU during the month of July to September 2014. Ethics committee approval was not required. A medication reconciliation form (see in annexure) was filled up by the clinical pharmacist. It was the duty of the clinical pharmacist to repeat a history from the relatives and fill up the form. The clinical pharmacist also studied the interactions between drugs. These were classified as

\section{Contraindicated}

High risk for dangerous interaction can't be used in combination.

\section{Serious}

Potential for serious type of interaction, monitoring required or alternate medicine may be needed.

\section{Significant}

Potential for significant type of interaction, monitoring required.

\section{Minor or no significant}

Interaction is unlikely, minor, or no significant.

Discrepancies and interaction if found were reported to the head of critical care and remedial measures were taken.

\section{RESULTS}

As we can see in Table 1 that almost $58 \%$ of medication history was taken from family recall with addition of outpatient notes. Some patients were referred from other nursing homes or intensive care units and hence in such patients medication history was taken from the hospitalization records and then reconfirmed with family members. To our surprise there was not a single patient who came to the hospital with their medication containers which is one of the easiest and safest methods to avoid medication errors. Almost $5 \%$ patient's medication history was derived from a recall by a family member. Discharge note from prior hospitalization was also a good source of information for medication history which has been confirmed with patients or relatives.

\section{Table 1: Patient history source}

\begin{tabular}{|c|c|c|}
\hline History taken from & $\begin{array}{l}\text { No of } \\
\text { cases }\end{array}$ & Percentage \\
\hline Discharge note & 5 & $3.05 \%$ \\
\hline Discharge note + family recall & 3 & $1.83 \%$ \\
\hline $\begin{array}{c}\text { Discharge note }+ \text { family recall+ } \\
\text { OP notes }\end{array}$ & 5 & $3.05 \%$ \\
\hline Discharge note + OP notes & 1 & $0.61 \%$ \\
\hline Family recall & 8 & $4.88 \%$ \\
\hline $\begin{array}{l}\text { Family recall + medication } \\
\text { container }\end{array}$ & 3 & $1.83 \%$ \\
\hline Family recall + OP notes & 95 & $57.93 \%$ \\
\hline $\begin{array}{l}\text { Medication administration record } \\
\text { from prior institution }\end{array}$ & 2 & $1.22 \%$ \\
\hline $\begin{array}{l}\text { Medication administration record } \\
\text { from prior institution + Family } \\
\text { recall }\end{array}$ & 11 & $6.71 \%$ \\
\hline $\begin{array}{l}\text { Medication administration record } \\
\text { from prior institution + patients } \\
\text { recall }\end{array}$ & 4 & $2.44 \%$ \\
\hline Medication container & 0 & $0 \%$ \\
\hline OP notes & 5 & $3.05 \%$ \\
\hline Patient recall & 3 & $1.83 \%$ \\
\hline Patient recall + Family recall & 4 & $2.44 \%$ \\
\hline Patient recall+ family recall & 1 & $0.61 \%$ \\
\hline Patient recall+ OP notes & 14 & $8.54 \%$ \\
\hline Total & & 164 \\
\hline
\end{tabular}




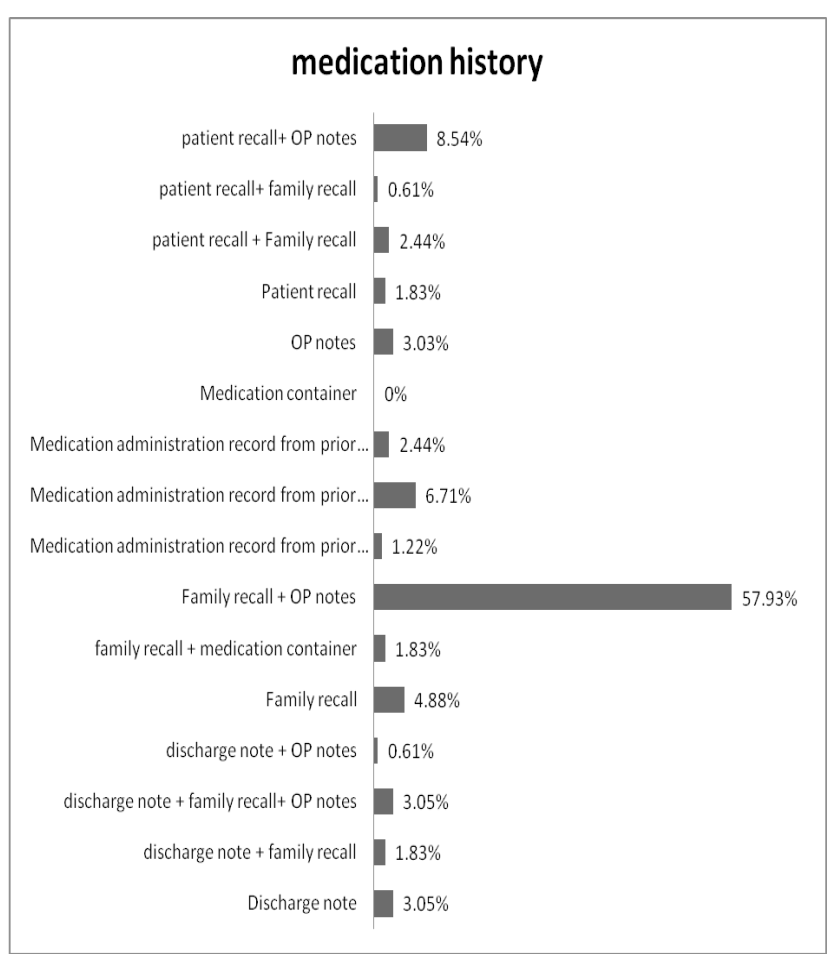

Figure 1: Medication history sources

\section{Table 2: Discrepancy classification}

\begin{tabular}{ccc}
\hline Discrepancy noted & No & Percentage \\
\hline History not written & 3 & $1.79 \%$ \\
improper history & 6 & $3.57 \%$ \\
interaction found & 72 & $42.86 \%$ \\
medication omission & 5 & $2.98 \%$ \\
medication omission + interaction & 4 & $2.38 \%$ \\
$\quad \begin{array}{c}\text { Nound } \\
\text { No history }\end{array}$ & 2 & $1.19 \%$ \\
No discrepancy & 76 & $45.23 \%$ \\
\hline
\end{tabular}

It is interesting to know that one patient and family were not even aware of what the patient was taking and the medication history was slaved from outpatient-notes and discharge notes. To our surprise in 4 cases we never got a medication history at all.

Detailed charting of sources of medication history can be seen in Figure 1. After repeat history taking by the clinical pharmacist and filling up of the medicine reconciliation form we did pick up discrepancies and interactions which were missed out by the doctors and the nurses.

From Table 2 we can see that $3.57 \%$ of the medication errors were due to improper history by the doctors and nurses. In $2 \%$ cases the medication history was not even written. In spite of detailed medication history being taken and transcribed in the section for history taken almost in $2.38 \%$ cases medications were omitted during transcription in the medication order-sheet. Please refer to Figure 2 for details of descrepancies noted.

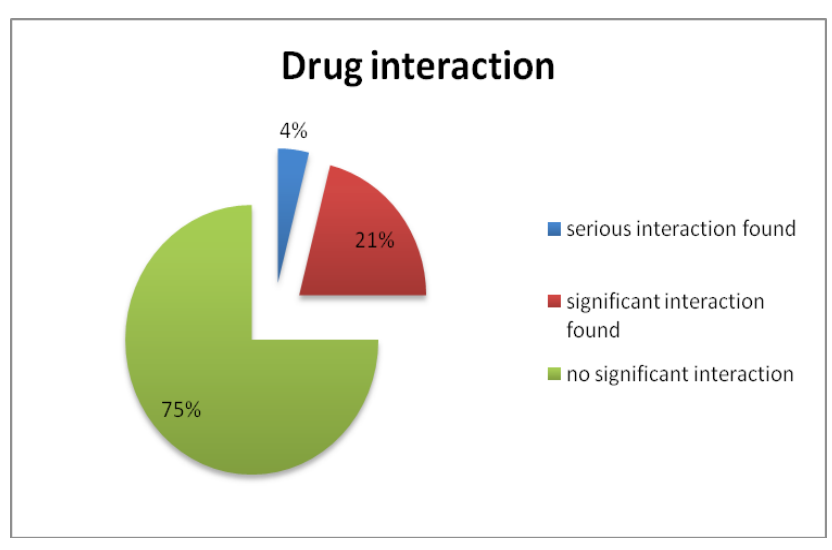

Figure 2: Discrepancy pie chart

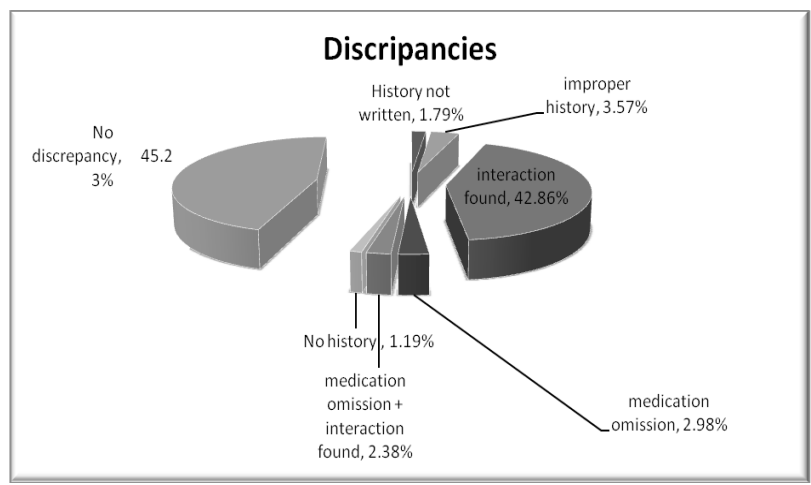

Figure 3: Charting for type of interaction

\begin{tabular}{ccc}
\multicolumn{2}{c}{ Table 3: Interaction profile } & \\
\hline Interaction type & No & Percentage \\
\hline $\begin{array}{c}\text { Serious } \\
\text { interaction found } \\
\begin{array}{c}\text { Significant } \\
\text { interaction found } \\
\text { no Significant } \\
\text { interaction }\end{array}\end{array}$ & 3 & $3.95 \%$ \\
\hline
\end{tabular}

Best possible medication history was taken out from various sources. This was then compared with the history and drug chart written by the on duty doctor. Some of the discrepancies had been noted.

$43 \%$ drug interactions were picked up as a result of this process of which $3.95 \%$ were serious and were $21.05 \%$ were significant. $75 \%$ cases no significant interaction seen. Please refer to Figure 3 and Table 3 for details.

\section{DISCUSSION}

As per the results of the above study it does appear that dedicated tracking of medication history seems to be the key in avoiding the potential serious threat to our patients.

This can possibly be done by

- Involvement of a clinical pharmacist in medication reconciliation

Indian Journal of Pharmacy Practice, Vol 8, Issue 3, Jul-Sep, 2015 
- Introduction of a document which needs to be refilled by the clinical pharmacist with leading questions clearly jotted down.

- Use of external sources like tin the internet and medication safety softwares inorder to scrutinize drug-drug interactions.

"Dedicated personnel for documentation and pick up these errors would help us to improve safety of our patients". In cases where significant interactions were picked up as a result of this exercise the treating team were also quite attentive to the occurrence of the same and hence heightened targeted monitoring in these cases.

\section{REFERENCES}

1. Roy V, Gupta P, Srivastava S. Medication errors: causes and prevention. Health Administrator 2011; 22(1): 60-4.

2. Larizgoitia AKI, Audera-Lopez C. The global burden of unsafe medical care: analytic modelling of observational studies. BMJ Qual Saf. 2013; 22(10): 809-15.

3. Reddy, Narra Gopal. Preventable Errors: Never Events. Medical Customer Safety 2014; 3(29): 817.

4. Ramesh M, Pandit J, Parthasarathi G. Adverse drug reactions in a south Indian hospital--their severity and cost involved. Pharmacoepidemiol Drug Saf. 2003; 12(8): 687-92.

\section{CONCLUSION}

This small study actually reinforced the adage that "you will find it only if you look for it".

Involving a data sheet for medication reconciliation with a dedicated clinical pharmacist does seem to play an important role in medication reconciliation. Regular audits in this respect will help in improving this aspect of healthcare.

\section{ABBREVIATIONS}

$\begin{array}{ll}\text { OP: } & \text { Out-patient } \\ \text { ICU: } & \text { Intensive care unit }\end{array}$

5. Dean FB, Vincent C, Schachter M, Barber N. The incidence of prescribing errors on hospital inpatients: An overview of the research methods. Drug Saf. 2005; 28(10): 891-900.

6. Medical errors may be the country's third-leading cause of death: advisory board Committee USA. http://www.advisory.com/daily-briefing/2013/09/24/ medical-errors-may-be-the-country-third-leading-cause-of-death. 